\title{
THE ROLE OF BUSINESS INCUBATORS IN THE DEVELOPMENT OF SUSTAINABLE CLUSTERS OF CULTURAL AND CREATIVE INDUSTRIES
}

\author{
A. ROMEIN \& J.J. TRIP \\ Faculty of Architecture and the Built Environment, Delft University of Technology, the Netherlands.
}

\begin{abstract}
Clusters of cultural and creative industries are rather widespread in and surrounding inner cities. The development and dynamics of these clusters are objects of study of various conceptual approaches: some aim at their role and significance for urban development, others at their development and dynamics as such. These latter approaches focus primarily on producers or consumers of cultural or creative goods. By contrast, this paper explores the role of a particular type of secondary or ancillary activity - the business incubator - in the development of these clusters. The paper is explorative and draws no explicit conclusions. Nevertheless, the incubator appears to be an ancillary activity that contributes in various manners to sustainable cluster development, i.e. not only by their output of young, trained entrepreneurs in possession of up-to-date knowledge and skills, but also by means of, for instance, their buildings and social networks.
\end{abstract}

Keywords: business incubators, clusters, cultural and creative industries, inner city, start-ups, vacant industrial building.

\section{INTRODUCTION}

Like industries in general, the recently conceptualised category of cultural and creative industries (CCIs) tend to cluster in specific urban localities. This category's subsector of high-content industries - including consumption in situ of local cultural heritage or performing arts, production of cultural products (e.g. film, media, music), design-based craft industries or applications of information and communication technologies (ICTs) - is mainly located in urban zones of transition, usually at the fringes of inner cities. This locational preference is due to their sensitivity to particular qualities of place at the neighbourhood scale [1]. According to Stevens [2: 2], these concern 'distinctive physical characteristics like mixed land use, ageing structures, and a wide range in type and quality of functions'.

In a paper on urban planning of cultural quarters in Glasgow and Dundee, McCarthy [3: 398] defines this type of cluster as 'a spatially limited and distinct area which contains high concentration of cultural facilities compared to other areas [...], though the specific activities within such a quarter may include ancillary activities such as libraries and informal recreation'. The focus of this paper is on the potentialities of business incubators as one particular type of ancillary activities to support sustainable growth and innovativeness of CCI clusters. Business incubators are businesses themselves but instead of cultural or creative goods, services or performances, they 'produce' start-ups; entrepreneurs that are trained to set-up a new firm. To the best of our knowledge, this contribution of incubators has not been explored explicitly yet. This paper makes a first move to fill this gap in our knowledge. 
In spite of McCarthy's definition, the CCI cluster is far from a well-defined and conceptually clear concept. It embraces a broad diversity of practices that differ from each other on various features - the above-mentioned distinction between consumption - versus production orientation is only one. Furthermore, their development and dynamics are objects of study of various research disciplines and conceptual models. These include urban spatial planning, culture-led urban regeneration, creative city, urban and economic geography, cultural economy and urban design. Regarding urban design, the question how it nurtures CCI clusters is typified by Stevens [2:3] as a still 'nascent area of enquiry'.

The same lack of an unambiguous practical demarcation and of conceptual clearness holds for the business incubator. Over all, these show a wide variety in, for instance, size, focus (highcontent or high-tech industries), incubatees (pre-start-ups, start-ups or more mature firms), ownership (public, private) and funding (public, non-public). Hence, it is not surprising that numerous attempts have been to define and classify incubators (for an overview see e.g. [4, 5]).

Our conceptual approach to explore how incubators may contribute to the development of CCI clusters in a sustainable way is based on the concept of quality of place, in a broad meaning. This approach is partly based on elements of some of the above-mentioned academic disciplines. We distinguish two types of qualities: place-based and cluster-based ones. The first type embraces qualities of the locality where CCI firms concentrate, whereas the second type is intrinsic to that concentration, i.e. interactions and interrelations between firms, secondary services, ancillaries and people - workers or visitors. Further, each of both types is subdivided into two types of 'space': respectively material and symbolic space as place-based qualities, and social and economic space as clusterbased qualities. Material and symbolic space involves the physical qualities and symbolic meanings of buildings and design and morphology of the urban environment. Social and economic space concerns quality of labour, linkages between firms and the role of social and business networks.

The relationships between these qualities of place and the dynamics of CCI clusters are reciprocal. Correspondingly, business incubators provide services to entrepreneurs, usually start-ups, in CCIs that fit within three dimensions that match the types of spaces: the building (cf. material and symbolic space), a programme of supporting services (cf. economic space) and networks (cf. social space).

The next section of the paper presents an analysis of the four types of spaces and the role these play in the development of the CCI clusters that are usually found in cities' central locations. After that, the three distinguished types of services supplied by incubators to CCI clusters are elaborated. Next, an overview of incubators' possible impacts on cluster dynamics is presented, and finally some concluding remarks will be presented.

\section{SPACES OF CCI CLUSTERS}

The city until the mid-20th century was characterised by 'mega spaces' of single-use corporate structures - industrial, commercial or residential. As Hutton [6: 212] observes, these have been broken up and transformed into 'a complex and variegated landscape which form much of the territorial domain of the cultural economy with its diversity of mostly smallscale enterprises in the form of cultural quarters or precincts'. This type of landscapes may also include traditional high streets of former residential quarters of workers in these corporate spaces. Separately, each of the four different types of spaces of our conceptual model has limited power to explain why and how CCIs agglomerate in specific sites of these current fine-grained urban landscapes of interpenetrating land-uses in inner cities. For, a CCI cluster 
is a multiplicity and to the extent that it can be understood by qualities of place, that is only by a mixture or assemblage of these four types of spaces [1,7-9].

\subsection{Material space}

Many of the observations on how material, or physical, space impacts on clustering of CCIs go through social processes and psychological values that underlie creative production. Nevertheless, some physical characteristics of old obsolete buildings in former corporate mega-spaces - mainly former factories or warehouses - have direct impacts on clustering of CCIs by providing accommodation. The first direct impact is the low rents that are usually charged, primarily by local governments as guardians of that built heritage left behind after bankruptcy or move of corporate firms. A low rent is not only a low barrier of entry but also enhances risk taking and facilitates experimentation by the (very) small firms that are typical for CCIs, hence contributing to innovativeness of the cluster. In addition, these old buildings usually offer qualities like high ceilings and doorways, natural light, and most of all large open spaces. Many firms in CCIs demonstrate a marked affinity for such spaces because of the opportunities these offer for adaptive re-use.

In spite of the benefits of obsolete cheap buildings, Wood \& Dovey [1] argue in favour of mixed landscapes of both these with new, more expensive buildings. That mix also service mature firms, either firms that matured within the cluster or newcomers, which are less experimental and are consolidating their markets, hence contributing to greater diversity of firms that reciprocally draw upon one another in CCI clusters.

\subsection{Symbolic space}

Many workers in CCIs also demonstrate affinity for the symbolic or even emotional values of former corporate spaces due to qualities as their 'look and feel', authenticity and roughness but also a sense of familiarity or contentment $[10,11]$. These qualities concern old industrial buildings, their in-between public spaces, and the typical urban morphology, building typologies and architectural styles and elements. Clare [12: 2] quotes an entrepreneur in the advertising cluster in Soho, London, who appreciated the grittiness, rawness and lack of 'that sticky corporate feel' of the neighbourhood. Such qualities may determine places' image, identity and reputation that attract new firms in CCIs.

Symbolic space serves as raw material that stimulates imaginative capacities of producers of creative and cultural commodities to think outside the box. However, the relationship between symbolic values of place and clustering of CCIs is broader than this. Boontharm [13: 279] points at the possibility of the reverse impact: the cultural industry studied in the paper - fashion - 'can transfer its potentials and benefits into the urban realm'. And Gibson (2008; see [14: 2833]) comments that places' symbolic attributes can be incorporated into aesthetic or expressive values of CCIs' products, music styles in his paper. In the course of time, clusters of producing firms, institutional ancillaries and 'specialised audiences' with a strong local identity can become a brand for a product that is based on tradition and reputation.

\subsection{Social space}

Place-based agglomeration of firms and workers in CCI clusters is considered by many to be a collective social process within a local vibrant and creative atmosphere that creates high 
levels of interaction conductive to production. As Martins [8: 127] emphasises, 'social practices are critical part of the work' in these clusters. Social network can be full of buzz - a transmitter of information, knowledge and ideas about new technologies, commissions or market trends across clusters. Buzz leads to interaction and, if expedient, to cooperation of workers and firms in projects.

These social practices are critical because of the production structure of CCI clusters that is typified by a high proportion of mutually intertrading and subcontracting micro-, small, and (a few) medium-sized firms. These place-based communities of firms depend strongly on intensive mutual contacts that involve, in the words of Grabher [15: 245], 'agencies, personal ties, localities and corporate networks which provide essential sources for project-based organizing [of practices of production: authors'addition]'. Grabher explores how the 'project ecology' has undercut the firm as the basic analytical unit of production organisation of a typical CCI, advertising industry in London.

Social practices as 'critical part of the work' [8] are related in various ways to material space. Elements of the material space such as small grain size, pedestrian friendly and permeable streetscapes, and 'open interfaces' between activities in the street and in buildings [1, 9, $14,16]$ all contribute to encounters of workers in CCIs that generate buzz. Buzz is also generated in so-called third places - hybrids between the social environments of home and workplace, like cafés, bars and clubs with day-, evening- and night-time opening hours. Martins [8] elaborates the role of third spaces by means of the concept 'extended workplace'. Many entrepreneurs and workers in the typical small firms distribute their work patterns over multiple settings: 'the base' - office or residence - and complementary semi-public and public ancillary spaces that are occasionally used for specific work practices. She distinguishes three types of ancillary spaces: the 'workafe' for autonomous and collaborative work; the 'meeting place' for work-related meetings with either clients or own staff; and the 'break-out space' for less work-intensive tasks such as informal internal meetings or just 'thinking'. Such spaces within walking distance contribute to make the area a good working neighbourhood.

\subsection{Economic space}

According to Porter's concept of industrial cluster [17, 18], industrial firms concentrate geographically for the ready availability of skilled labour, of supporting and ancillary trades, and of different firms in different stages and branches of production within the field of specialisation. Martin \& Sunley [17] criticise Porter's concept for the lack of spatial range or limits to his clusters: these can be either dispersed across countries or locally concentrated. With regard to contemporary arts industries, Grodach et al. [19] point at their great propensity to cluster in US metropolitan areas, whereas other authors scale down to more fine-grained interwoven configurations of firms specialised in particular CCIs - usually small or micro - at particular localities within cities [12, 17].

Firms in these particular localities can benefit from concentrations of potential clients; ancillary services like finance, advanced business services and educational institutions; and a labour pool that supplies varied skills. Moreover, co-presence on that small scale is critical for firms in the project ecology that is characterised by successive temporary business relations.

\section{DATA COLLECTION}

The data for the section on services provided by business incubators in CCIs are obtained by the transnational project InCompass, co-funded by the EU INTERREG IV-C programme. It 
Table 1: Cases studied.

\begin{tabular}{|c|c|c|}
\hline City/region & Month/year & Incubators \\
\hline Rotterdam (NL) & May 2012 & $\begin{array}{l}\text { Creative Factory } \\
\text { DNAMO }\end{array}$ \\
\hline Milan (IT) & June 2012 & $\begin{array}{l}\text { Fabbrica del Vapore } \\
\text { Hub Milano } \\
\text { Make a Cube } 3\end{array}$ \\
\hline $\begin{array}{l}\text { Øresund Region } \\
(\mathrm{DK}, \mathrm{SE})\end{array}$ & $\begin{array}{l}\text { November } \\
2012\end{array}$ & $\begin{array}{l}\text { Malmö Incubator } \\
\text { Media Evolution City (must be Malmö) } \\
\text { Company Care (Copenhagen) }\end{array}$ \\
\hline Lisbon (PT) & April 2013 & CoWork Lisboa \\
\hline Patras (GR) & June 2013 & Carnival Lab \\
\hline Asturias (SP) & $\begin{array}{l}\text { November } \\
2013\end{array}$ & $\begin{array}{l}\text { Factoría Cultural (Aviles) } \\
\text { School of Female Entrepreneurs } \\
\text { LABoral } \\
\text { Valnalón }\end{array}$ \\
\hline Medway (UK) & February 2014 & coFWD/Project 161 \\
\hline London (UK) & $\begin{array}{l}\text { February and } \\
\text { September } \\
2014\end{array}$ & $\begin{array}{l}\text { Camden Collective } \\
\text { Cockpit Arts } \\
\text { Trinity Buoy Wharf } \\
\text { Cultural Industries Development Agency (CIDA) } \\
\text { London Met Accelerator } \\
\text { Centre for Creative Collaboration (C4CC) }\end{array}$ \\
\hline
\end{tabular}

was carried out between 2012 and 2014 by a consortium of academic researchers, urban policy makers and incubator managers from 12 partner cities or regions in seven EU countries. The consortium paid study visits to 21 incubators specialised in CCIs in eight of these cities or regions (Table 1).

During these study visits, data were obtained by presentations, discussions and some in-depth interviews with incubator managers, start-ups and local and regional policy-makers. When necessary, additional information was gathered afterwards from the visited incubators. The results of the case studies have been validated by local experts from the regions visited.

It was not the explicit aim of InCompass to assess incubators' impacts on development of CCI clusters. Consequently the visited cases were not by definition part of a distinct CCI cluster, in spite of the fact most of their buildings had a manufacturing or commercial past. Their possible impacts on cluster development came up for discussion occasionally during the study visits, and the huge amount of information collected makes an exploration of this role possible. Nevertheless, the overview of incubators' possible impacts on cluster dynamics is only explorative: for a more thorough, tested picture of that role, more in-depth and targeted empirical research is required. 
84 Urban Regeneration and Sustainability

Table 2: Cases according to the services provided.

\begin{tabular}{lc}
\hline Services & Number \\
\hline Workspaces, networking and support & 15 \\
Workspaces and networking & 2 \\
Workspaces and support & 1 \\
Networking and support & 2 \\
Workspaces & - \\
Networking & - \\
Support & - \\
n.a. & 1 \\
Total & 21 \\
\hline
\end{tabular}

\section{SERVICES OF BUSINESS INCUBATORS}

Basically, business incubators provide a dedicated and supportive environment for start-up companies to be founded; to be nurtured in order survive their infancy when they are particularly vulnerable [20, 21]; and to grow into a new firm that can stand on its own feet in the business world outside the incubator. As such, they span a bridge from initial ideas for an innovative product, service or concept of a would-be entrepreneur to the early steps of bringing that on the market in an elaborated form. For the necessary chain of stages this process involves, they usually provide an incubation programme of a certain length, mostly up to about 3 years, to which the starting entrepreneur commits itself. InCompass data distinguish three dimensions of services supplied during the programme: the building, support programme and social business networks. Two-third of the visited incubators supplied all three (Table 2).

By far most of the 21 incubators listed in Table 1 were set up in obsolete or otherwise vacant buildings in cities' zones of transition. The histories of these buildings are very diverse: a grain silo and a warehouse in former port areas; a complex of a ship building and dry-dock company, including boardrooms; factory buildings of textile, furniture, leather, steel and train-building industries; a bank building, two university buildings (as spin-off of the universities), and typical high street buildings. Most were bought of the former owner(s), if these were still traceable, and next refurbished by local or regional governments. After being refurbished and put into use as incubator, these are either administered and managed by that government; by a partnership of public and semi-public institutions, mostly educational institutions; or leashed to either a private company or, in the UK, a charity, trust or BID (Business Improvement District).

Overall, the visited incubators focus on a rather broad diversity of CCI branches. Some are rather specialised, in particular in ICT-based applications like digital media, serious games development or web-design, but others include a seemingly random collection of branches, including audio-visual industries (photography, film making, music recording); traditional crafts like fashion, furniture and ceramics; and performing or fine arts.

\subsection{Building}

In general terms, most incubator buildings offer affordable work spaces and shared facilities. These latter include a staffed counter at the entrance; an administrative office; meeting spaces 
varying from coffee corners and a kitchen to meeting and conference rooms; technical services like broadband internet; and expensive equipment like 3D printers. Some cases have also exhibition spaces available, or organise open days or annual events hosted in the building to display prototypes made by start-ups, hopefully to be visited by potentially interested (future) buyers or business partners. Not only start-ups who work in the building rent spaces or equipment: some incubators also make these available, on payment, to external parties like companies or local schools for practical training hours.

Both incubator managers and incubatees show a manifest affinity to social space qualities within the building. These include, for instance, an open layout of floors; transparent glass walls of working spaces; and coffee corners and basic kitchens at strategic locations; all to encourage unplanned informal meetings of start-ups. In addition, the symbolic values of these old buildings, and their immediate urban surroundings, also matter. A telling example is CoWork Lisboa: it had various options to settle at its foundation but choose to move into a marked piece of industrial heritage, a robust vacant textile factory, after the symbolic value of that premise was underlined in a questionnaire among potential tenants. On the other hand, some companies that have grown larger and consolidated their markets do not want to be associated with the community of vulnerable start-ups any longer and may decide to leave the incubator.

\subsection{Support services}

Most incubators offer training and mentorship programmes to improve start-ups' entrepreneurial and management skills. Besides, these programmes may also help start-ups to find access to affordable loans, or other opportunities to raise money from existing funds, and to bring start-ups into contact with companies that show interest in their prototypes. These types of support are provided by various types of professionals, i.e. staff members of incubators (although most incubators have a lean staff size); experienced entrepreneurs who (still) rent space in the building; or staff members of external professional organisations that have a partnership agreement with the incubator. Examples of these organisations are local government departments, universities of applied sciences, and accountancy and financial institutions. A peculiar case is Malmö Incubator, specialised in ICT applications, which keeps its staff members' skill levels up to date by refresh courses with partner companies and institutions in Silicon Valley. Two of the 21 visited incubators had no formal support service programme but stimulate self-management of 'co-assistance' by incubatees.

\subsection{Networks}

Most incubators attempt to build-up social business networks of start-ups who work within their premises. 'Strategies' to stimulate networks within the building are creating a lay-out of open spaces or placing shared facilities like the coffee machines in a way that encourages unplanned, spontaneous encounters with the aim to generate buzz. Glass walls of working spaces and placing start-ups in related, but not identical activities together in co-working spaces may also help. Besides, meetings are organised to inspire network formation within the incubator in a more planned manner, e.g. Friday afternoon drinks or monthly lunches.

Another type of networks connects incubatees with firms and institutions in the outside world, including those that have a partnership agreement with the incubator. Examples are educational institutes, funding agencies, managerial offices and, last but not least, potential 
clients who are interested in their ideas or prototypes. Cooperation of start-ups in incubators with educational institutes may take the shape of internships, which is at the benefit of both the start-ups and the students. The organisation of open days or common events, e.g. the annual show by fashion designers in the Milan' Fabbrica del Vapore, are strategies to bring start-ups into contact with potential clients. Overall, these potential clients can be local firms - some incubators indeed aim purposively to contribute to strengthening local or regional industrial clusters - but others may be 'long distance partners', like those of Malmö Incubator in Silicon Valley.

\section{POSSIBLE IMPACTS OF INCUBATORS ON CCI CLUSTERS}

This section explores the possible contributions of the services supplied by business incubators to the four types of spaces that together impact upon the growth and development of CCI clusters.

\subsection{Material space}

Two typical features of firms in CCIs, small size and unstable revenues, hold most for startups. Indeed, business incubators provide a supportive environment for these to survive their infancy. Although rents of old vacant buildings are relatively low, these are still impossible to afford monthly for most start-ups, in particular if supplemented with service charges. They save on expenses due to the typical feature of incubators to offer shared facilities and services.

Furthermore, in particular, larger vacant factory or warehouse buildings offer the incubator space and flexibility (movable walls) to create a diversity of dimensions and types of workspaces. In many visited cases, this diversity ranged from a single desk plus chair in a co-work space for a few weeks to a long-range rental contact of an equipped office for exclusive use. This diversity suits with the diversity and changeability in the course of time of the demand (paying capacity) for work-space by start-ups. Incubators in large industrial buildings often have spaces - either unsuited or superfluous for renting out as workspaces - available for temporary uses such as meetings, exhibitions, rehearsal or performances, which are important to facilitate project-based work, try-outs and displays of products. Overall, incubators lower the barrier of entry for start-ups to the material space of clusters, hence contributing to their occupancy rate.

\subsection{Symbolic space}

Obsolete factory or warehouse buildings in corporate mega-spaces of the industrial economy that are pervaded with roughness and authenticity offer opportunities for experimenting, at least more than new shiny office buildings. As young start-ups are in particular in a stage of experimenting and thinking outside the box, these building are highly appropriate for incubators. Furthermore, early start-ups in CCIs may have a greater affinity for the image, identity and reputation of these buildings than mature firms, also those in CCIs, that are consolidating their market position in the 'upper ground' [22] of the mainstream economy.

In reverse, incubators can contribute to the symbolic space of clusters if they are actively outward oriented, e.g. by means of open days, events to display the fruits of experiments by start-ups, or opening up their café or lunch restaurant for all workers in the cluster. The 
visibility and approachability of experimenting incubatees contribute to the image, identity and reputation of the cluster, and may accordingly attract new talented workers and would-be entrepreneurs.

\subsection{Social space}

Incubatees can contribute to the dynamics of CCI clusters by their contribution to the generation of buzz, first and foremost by 'hanging around' in third places and extended work places. Crucial is that these young people bring 'fresh blood' into the cluster: many are recently graduated and acquainted with topical knowledge, the newest technologies and new ideas. Besides, incubator may house ancillary spaces in the extended workplace of workers in the CCI cluster [8]. The above-mentioned day-time café or lunch restaurant may be such a 'workafe', meeting place or break-out space.

Incubators also contribute to the social space of CCI clusters if they apply a purposive strategy to reinforce or build social networks that put the incubatee community within the incubator in contact with entrepreneurs elsewhere in the cluster. This creates a protective environment for these newcomers in the cluster to become gradually acquainted with the 'knowledge, social norms and conventions of mutual trusts become the pillars of a network of interaction and exchange' (Desrochers, 2001; see [23: 558]), hence laying a foundation for new projects. Incubators probably have the best and most up-to-date overview of both opportunities and potential partners within and outside its premises for new projects. This foundation is strongest if the sectoral profile of CCI in the cluster and in the incubator is similar to a certain extent.

\subsection{Economic space}

Fine-grained interwoven configurations of firms, specialising in particular primary activities, are crucial in local economies that are based on temporary projects with successive multiple business relations. To the extent that start-ups in the incubator are included in these configurations, i.e. develop business linkages with external firms in the CCI cluster, the incubator extends this configuration. When new firms that leave the incubator settle in the cluster itself, the same holds for them. In other words, incubators supply new entrepreneurs with fresh views to the cluster who otherwise wouldn't have been able to settle in it.

Interactions by firms with ancillary institutional actors such as local government, knowledge institutions and advanced business services, are crucial in the development of CCI clusters. Incubators can act as mediators between start-ups and these external actors as respectively receivers and providers of business services. Without incubators it is practically impossible for most start-ups to do business with these formal institutions due to, among other reasons, mutual misunderstandings of their highly different way of working. Incubators get these two different worlds acquainted with one another, hence reducing these misunderstandings.

\section{CONCLUDING REMARKS}

In this paper, business incubators are typified ancillary activities in CCI clusters. Most of these activities serve a single or a very limited range of purposes, for instance because these are most typical for either consumption-oriented clusters (e.g. gift shops, cafés, recreation facilities, etc.) or production-oriented clusters (e.g. labour force and business supporting 
institutions). However, the business incubator can contribute to the performance and further development of CCI clusters in a sustainable way in quite a few different manners. What is more, an incubator as a new 'node' in a CCI cluster contributes more than single purpose ancillaries to the self-reinforcing process of clustering due to the so-called network effect: a new node (new firm, cultural venue, education institution or star artist) adds value to many nodes that are already in a cluster due to new network interactivities [1: 53].

The contribution of incubators to the development of CCI clusters, as explored in this paper, involves four different types of spaces of these clusters: material, symbolic, social and economic. The explanation of their contribution requires the assemblage of these types of spaces. Furthermore, the qualities of space of CCI clusters also impact upon incubators: their relationships are mutual rather than unilateral.

Finally, the contribution of incubators to the growth and development of innovative clusters also depends on factors and processes that are are not related to 'place and space'. One other critical factor is the incubator policy regarding the sectoral profile of its incubatees in relation to either the specialisation or diversity of the cluster as a whole.

\section{REFERENCES}

[1] Wood, S. \& Dovey, K., Creative multiplicities: urban morphology of creative clustering. Journal of Urban Design, 20(1), pp. 52-74, 2015. http://dx.doi.org/10.1080/13574809.2014.972346

[2] Stevens, Q., Creative milieu: how urban design nurtures creative clusters. Journal of Urban Design, 20(1), pp. 1-7, 2015. http://dx.doi.org/10.1080/13574809.2015.981393

[3] McCarthy, J., The application of policy for cultural clustering: current practice in Scotland. European Planning Studies, 14(3), pp. 397-408, 2006. http://dx.doi.org/10.1080/09654310500420958

[4] Hackett, S.M. \& Dilts, D.M., A systematic review of business incubation research. Journal of Technology Transfer, 29(1), pp. 55-82, 2004. http://dx.doi.org/10.1023/B:JOTT.0000011181.11952.0f

[5] Barbero, J.L., Casillas, J.C., Ramos, A. \& Guitar, S., Revisiting incubation performance: how incubator typology affects results. Technological Forecasting and Social Change, 79(5), pp. 888-902, 2012.

http://dx.doi.org/10.1016/j.techfore.2011.12.003

[6] Hutton, Th.A., Cities and the Cultural Economy, Routledge: London \& New York, 2016.

[7] Montgomery, J., Cultural quarters as mechanisms for urban regeneration. Part 1: Conceptualising cultural quarters. Planning, Practice and Research, 18(4), pp. 293-306, 2003. http://dx.doi.org/10.1080/1561426042000215614

[8] Martins, J., The extended workplace in a creative cluster: exploring space(s) of digital work in Silicon Rondabout. Journal of Urban Design, 20(1), pp. 125-145, 2015. http://dx.doi.org/10.1080/13574809.2014.972349

[9] Bahar Durmaz, S., Analyzing the quality of place: creative clusters in Soho and Beyoglu. Journal of Urban Design, 20(1), pp. 93-124, 2015. http://dx.doi.org/10.1080/13574809.2014.972348

[10] Smit, A.J., The influence of district visual quality on location decisions of creative entrepreneurs. Journal of the American Planning Association, 77(2), pp. 167-184, 2011. http://dx.doi.org/10.1080/01944363.2011.567924 
[11] Hutton, Th.A., Spatiality, built form, and creative industry development in the inner city. Environment and Planning A, 38, pp. 1819-1841, 2006. http://dx.doi.org/10.1068/a37285

[12] Clare, K., The essential role of place within the creative industries: boundaries, networks and play. Cities. http://dx.doi.org/10.1016/j.cities.2012.05.009

[13] Boontharm, D., Creative milieu of fashion and reuse in Tokyo, Bangkok and Singapore. Journal of Urban Design, 20(1), pp. 75-92, 2015. http://dx.doi.org/10.1080/13574809.2014.972347

[14] Rantisi, N.M. \& Leslie, D., Materiality and creative production: the case of the Mile End neighbourhood in Montréal. Environment and Planning A, 42, pp. 2824-2841, 2010. http://dx.doi.org/10.1068/a4310

[15] Grabher, G., The project ecology of advertising: tasks, talents and teams. Regional Studies, 36(3), pp. 245-262, 2002. http://dx.doi.org/10.1080/00343400220122052

[16] Jacobs, J., The Death and Life of Great American Cities, Random House: New York, 1961.

[17] Martin, R. \& Sunley, P., Deconstructing clusters: chaotic concept or policy panacea? Journal of Economic Geography, 3, pp. 3-15, 2003. http://dx.doi.org/10.1093/jeg/3.1.5

[18] CLUSTER COLLABORATION, available at www.clustercollaboration.eu/clusterdefinitions

[19] Grodach, C., Foster, N. \& Murdoch III, J., Gentrification and the artistic dividend. Journal of the American Planning Association, 80(1), pp. 21-35, 2014. http://dx.doi.org/10.1080/01944363.2014.928584

[20] Aerts, K., Matthyssens, P. \& Vanderbempt, K., Critical role and screening practices of European business incubators. Technovation, 27(5), pp. 254-267, 2007. http://dx.doi.org/10.1016/j.technovation.2006.12.002

[21] Al-Mubaraki, H.M. \& Busler, M., Business incubators: findings from a worldwide survey, and guidance for the GCC states. Global Business Review, 11(1), pp 1-20, 2010. http://dx.doi.org/10.1177/097215090901100101

[22] Cohendet, P, The anatomy of the creative city. Industry and Innovation, 17(1), pp. 91-111, 2010. http://dx.doi.org/10.1080/13662710903573869

[23] Sacco, P.L., Ferilli, G., Tavano Blessi, G. \& Nuccio, M., Culture as engine of local development process: system-wide cultural districts I: theory. Growth and Change, 44(4), pp. 555-570, 2013.

http://dx.doi.org/10.1111/grow.12020 